\title{
Short communication: A note on the correction for the effect of freezing on the outcome of pregnancy-associated glycoprotein measurement in blood and serum of cows
}

\author{
F. Stahmann, ${ }^{1}$ M. Gauly, W. Holtz, and U. König von Borstel \\ Abteilung Produktsysteme der Nutztiere, Department für Nutztierwissenschaften, Georg-August-Universität, 37075 Göttingen, Germany
}

\section{ABSTRACT}

Early pregnancy detection is a measure of considerable economic relevance for dairy cattle breeders, and analysis of pregnancy-associated glycoprotein (PAG) values in blood is one of the methods implemented in practice. Starting from d 30 postconception, cows are considered to be pregnant at PAG levels of $2.0 \mathrm{ng}$ of $\mathrm{PAG} / \mathrm{mL}$ of blood and higher. However, little is known about preanalytic sources of errors that might affect PAG values. Based on blood samples from 65 dairy cows, the present study showed that freezing of samples, such as may be the case during shipping in wintertime, will lower PAG values considerably. Therefore, a BlandAltman analysis was used to derive a correction factor. Overall, the mean differences ( \pm standard deviation) between frozen and respective fresh samples was -5.5 $\pm 7.4 \mathrm{ng}$ of $\mathrm{PAG} / \mathrm{mL}$ of blood and $0.9 \pm 6.1 \mathrm{ng}$ of $\mathrm{PAG} / \mathrm{mL}$ of serum. However, the Bland-Altman plot revealed a concentration-dependent effect of freezing on PAG values with higher variability and larger declines at higher PAG levels. Therefore, to minimize chances of false-negative results, different correction factors are suggested for different levels of PAG (e.g., based on the upper bound of the $95 \%$ confidence interval 0.67 for PAG levels between 2.0 and $3.9 \mathrm{ng}$ of $\mathrm{PAG} / \mathrm{mL}$ and 0.25 for PAG levels between 4.0 and $7.9 \mathrm{ng}$ of PAG/ $\mathrm{mL}$ ). With these concentration-dependent correction factors, implementation into practice will be possible. The accuracy is adequate because no quantitative information but qualitative results (pregnant vs. nonpregnant) are required. However, due to larger chances of false-negative results, the application of the correction factor should only be a last resort if temperature exposure of a sample is unknown.

Key words: dairy cow, pregnancy test, pregnancyassociated glycoprotein, sample freezing

Received February 26, 2013.

Accepted June 15, 2013.

${ }^{1}$ Corresponding author: Friederike.Stahmann@t-online.de

\section{Short Communication}

Pregnancy diagnosis is an essential component of effective reproductive management, in particular in the dairy industry. During the last $30 \mathrm{yr}$, with increasing levels of milk production, conception rates have gradually deteriorated. Each day delay until establishment of pregnancy causes a loss of up to $\$ 3.21$ to $\$ 5.13$ (Hoedemaker et al., 2007; Lührmann, 2011). In cows, pregnancy is most commonly diagnosed by rectal palpation with or without the support of ultrasonography, occasionally with the aid of the milk progesterone test and, to a gradually increasing degree, determination of pregnancy-associated glycoproteins (PAG) in blood. Pregnancy-associated glycoproteins are produced in the placenta of pregnant cows (Zoli et al., 1991; Hughes et al., 2000) and may be measured in maternal blood by way of RIA (Sasser et al., 1986; Zoli et al., 1992) or ELISA using monoclonal (Green et al., 2005) or polyclonal antibodies (Friedrich and Holtz, 2004, 2010). Under normal conditions, from d 28 of pregnancy onward, PAG levels exceed $2.0 \mathrm{ng} / \mathrm{mL}$, and the reliability of pregnancy diagnosis at that stage approaches $94 \%$ (Friedrich and Holtz, 2010). In some cases, residual PAG from the previous pregnancy may interfere (Zoli et al., 1992). Little information is available concerning sources of error that might compromise the reliability of the test. From collection to analysis, blood samples are exposed to a period of storage on farm, shipment to the laboratory, and another period of storage and handling at the laboratory. In the course of these events, samples might have been deliberately for storage purposes or accidentally exposed to freezing temperatures. Recent studies (Stahmann et al., 2012) indicate that ambient temperature during storage and shipping may affect the outcome of the test. Therefore, the present investigation addresses the effect of freezing on the result of the PAG test and constitutes an attempt to devise a correction factor that may be applied if blood samples are known to have been frozen.

Blood samples from 65 clinically sound, 3- to 28-wkpregnant Holstein-Friesian and Brown Swiss cows of a commercial dairy herd were collected for the pres- 
ent study. The sampling was done in a single day by 1 person. All procedures were in accordance with national animal welfare regulations. The $3-\mathrm{mL}$ blood samples were drawn by venipuncture from the vena epigastrica cranialis superficialis. From each cow, 3 samples of $3 \mathrm{~mL}$ each were collected into 5 - $\mathrm{mL}$ plastic tubes (Sarstedt AG \& Co., Nümbrecht, Germany) and stored on crushed ice for $2 \mathrm{~h}$. Thereafter, 2 of the samples were centrifuged at $3,000 \times g$ for $10 \mathrm{~min}$. The serum of one of them was analyzed for PAG content immediately. The other one and the sample that had not been centrifuged were stored for 2 wk at $-20^{\circ} \mathrm{C}$ before they were analyzed as well. The ELISA used for PAG determination was described in detail by Friedrich and Holtz (2010). All analyzes were pipetted twice in triple repetition. Interassay and intraassay coefficients of variation at $0.8 \mathrm{ng} / \mathrm{mL}$ were 16 and $13 \%$ for serum, respectively (Friedrich and Holtz, 2010).

As PAG values did not follow a normal distribution, data were log-transformed to achieve a near-normal distribution. Both transformed (derivation of significance values) and untransformed data (derivation of means and standard errors) were analyzed using the following mixed model (PROC MIXED; SAS version 9.2; SAS Institute Inc., Cary, NC) to assess the influence of freezing on PAG values in blood and serum:

$$
\mathrm{y}=\mu+\text { treatment }+ \text { plate }+ \text { animal }+\mathrm{e},
$$

where y represents the mean PAG value as provided by the Magellan software (Tecan Group Ltd., Männedorf, Germany), $\mu$ represents the overall mean, treatment represents the storage temperature of the sample (room temperature or freezing at $-20^{\circ} \mathrm{C}$ ), plate represents a blocking factor of the analysis, animal represents the random animal effect accounting for repeated observations per animal, and e represents the random error.

In addition, to obtain 95\% confidence intervals and to visualize the potential for individual variation in values before and after freezing, a Bland-Altman analysis (Bland und Altman, 1986) was used. The Bland-Altman plot visualizes the effect of low-temperature freezing on PAG levels by plotting the mean of data pairs (PAG level of a sample before and after freezing) against the corresponding difference (PAG level after freezing PAG level before freezing) of each data pair. In contrast to the widely used correlation coefficients that indicate the degree of a linear relationship between 2 variables (Grouven et al., 2007), the Bland-Altman method describes the degree of agreement between 2 groups of measurements. When investigating the accuracy of a given method, the Bland-Altman plot is thus a more suitable method compared with correlation coefficients.

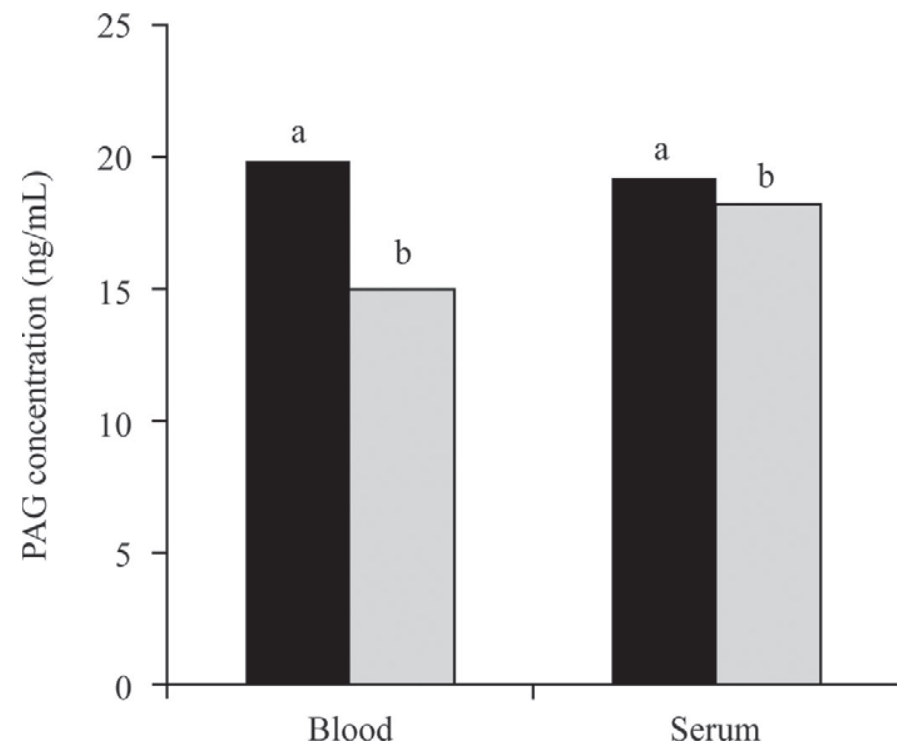

Figure 1. Mean pregnancy-associated glycoprotein (PAG) levels (ng of PAG/mL of blood) in cows' blood $(\mathrm{n}=65)$ and serum $(\mathrm{n}=$ 62 ) before (black bars) and after freezing (white bars). Different letters (a and b) indicate statistically significant differences at $P<0.05$. Presented means are derived from untransformed data.

Storage temperature affected PAG values in both blood and serum, with PAG levels decreasing significantly $(P \leq 0.05)$ after freezing (Figure 1$)$. However, the decrease in PAG levels appeared to be concentration dependent (Figures $2 \mathrm{~A}$ and $2 \mathrm{~B}$ ). In the present study, the Bland-Altman plot revealed a nonlinear relationship between the 2 treatment methods. Although at very low initial PAG levels, the levels tended to increase after freezing, PAG levels showed a decline after freezing at higher initial levels, and this decline tended to be more pronounced the higher these initial levels were.

This inconsistent behavior of PAG values suggests differential effects of freezing, such as alteration of PAG molecules (leading to decreased PAG concentrations) and sublimation of water (leading to increased PAG concentrations in the remaining sample). Such errors caused by storage conditions are common under practical conditions and have frequently been described (Kroll und Elin, 1994; Kraft, 2006; Lippi et al., 2006).

In addition to the individual data pairs, Figure 2A (blood) and Figure 2B (serum) show the mean difference and $95 \%$ confidence interval of the differences between PAG values in frozen and fresh samples. For blood, the mean $( \pm \mathrm{SD})$ difference was $-5.5 \pm 7.4 \mathrm{ng}$ of $\mathrm{PAG} / \mathrm{mL}$, with a $95 \%$ confidence interval of 8.9 to -20.0 . Therefore, to obtain a value that represents with 95\% certainty the lower bound of the true PAG value in a blood sample that potentially was frozen during transport, a value of 8.9 would have to be subtracted 
A)

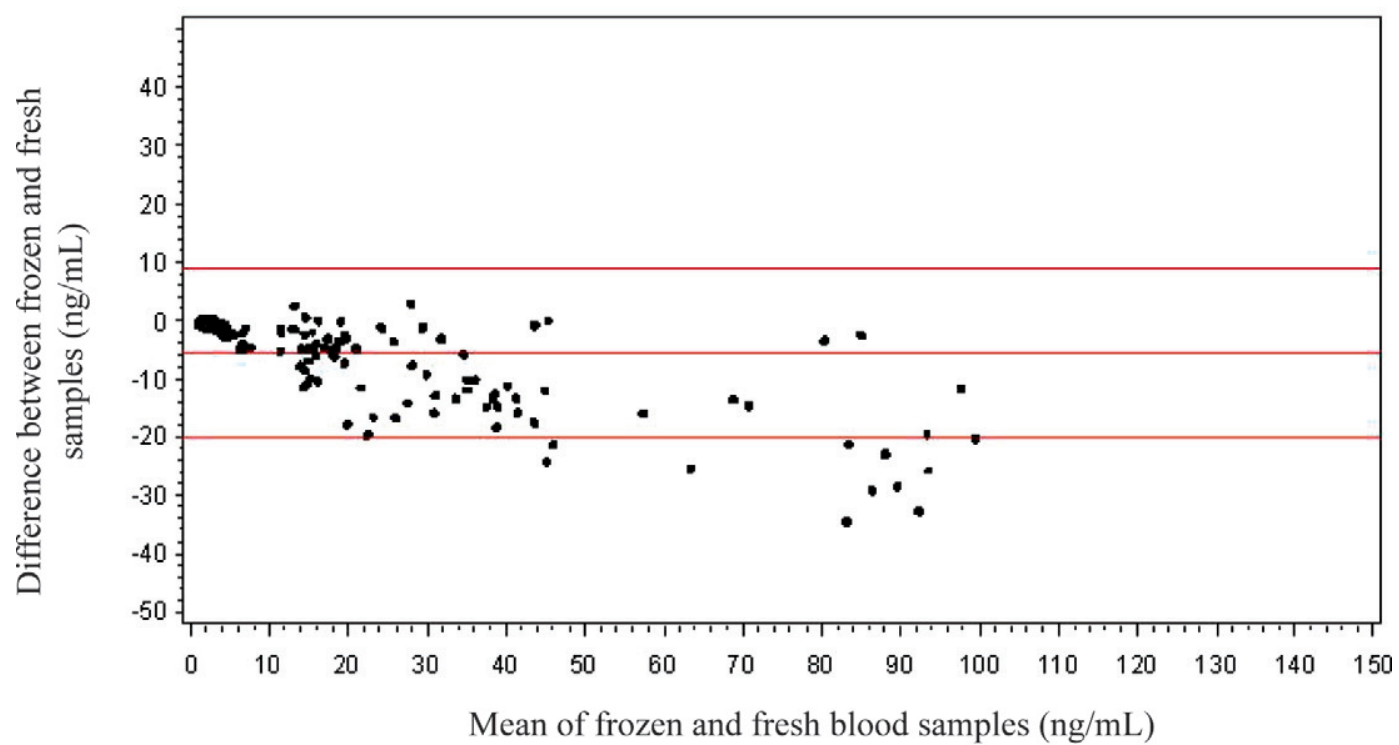

B)

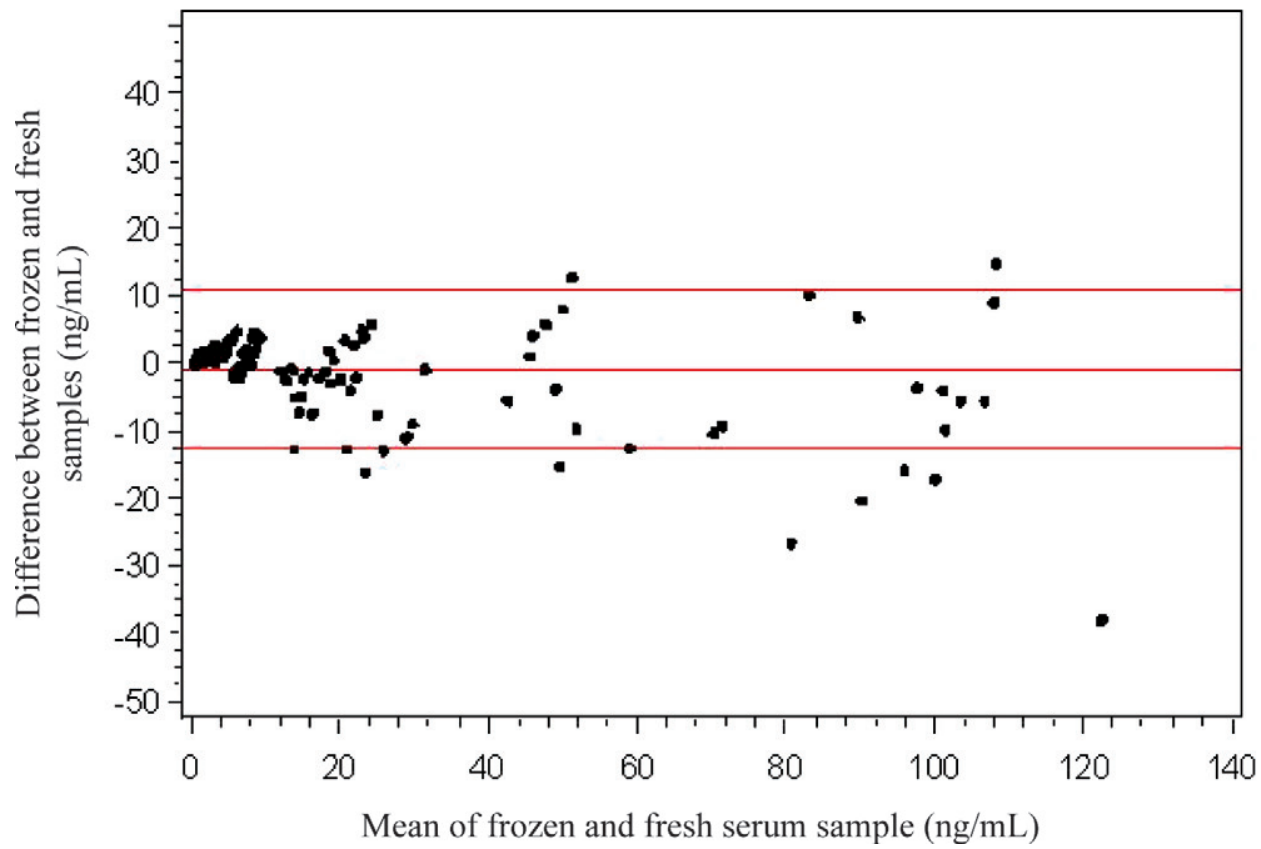

Figure 2. Bland-Altman plot depicting the average of each data pair (panel A: frozen and fresh blood sample; panel B: frozen serum and fresh blood sample) plotted against the respective differences of each data pair (frozen sample - fresh sample) as well as the overall mean difference (middle line) and upper and lower bound of the $95 \%$ confidence intervals for the difference (upper and lower lines). Color version available in the online PDF.

from the measured value. With serum, the situation was similar, with a mean difference in PAG values of fresh and frozen samples of $-0.9 \pm 6.1 \mathrm{ng}$ of PAG $/ \mathrm{mL}$ and the $95 \%$ confidence interval ranging from 10.9 to -12.8 .
Clearly, the high mean differences as well as the large confidence intervals are unacceptable for routine pregnancy detection in practice. For example, a sample containing $6 \mathrm{ng}$ of PAG/mL of blood would clearly indicate that the sampled cow is pregnant. However, if it were 
uncertain whether the sample was frozen during shipping and the correction factor of 8.9 were subtracted, a negative value would result, and the cow would falsely be identified as nonpregnant, if the sample never was frozen. Even the use of a less-stringent correction factor such as the subtraction of the mean difference plus 1 standard deviation, which would provide the lower bound for $68.2 \%$ of the true (control) values, would result in samples with concentrations below $3.9 \mathrm{ng}$ of $\mathrm{PAG} / \mathrm{mL}$ in false-negative results \{e.g., 3.8 (original value after potential freezing $)-[-5.5$ (mean) +7.4 $(\mathrm{SD})]=1.9\}$.

Therefore, a universal correction factor appears to be too inaccurate for practical purposes. Instead, the concentration dependence should be taken into account and different correction factors applied, depending on the level of PAG in the sample. Hence, data for both blood and serum (Table 1) were each assigned to 6 groups depending on the initial PAG level, and mean differences as well as $95 \%$ confidence intervals were calculated for each group separately.

Using the upper bound of the $95 \%$ confidence interval as a correction factor as presented in Table 1, reliable claims regarding the pregnancy status can be made starting from PAG values of $2.7 \mathrm{ng}$ of $\mathrm{PAG} / \mathrm{mL}$. At lower concentrations, in most cases, application of the respective correction factor will yield a value below the threshold of $2.0 \mathrm{ng} / \mathrm{mL}$. Thus, pregnancy could not be attested without doubt at these lower levels, if the possibility of freezing of the samples could not be ruled out. A false-negative result possibly has the consequence that cows are subjected to hormone-assisted heat induction for repeat breeding, which, however, would result in abortion/resorption of the existing embryo. To be on the safe side, it would be advisable to classify these animals as "doubtful" and recommend having another sample analyzed 1 wk later. Alternatively, we recommend ensuring frost-protected shipping of samples (e.g., via use of special packaging material; for example, envelopes insulated with air cushioning for sending diagnostic material at room temperature).

For serum, the situation is slightly different compared with blood. Freezing resulted in increased PAG levels at concentrations of less than $8.0 \mathrm{ng}$ of PAG/ $\mathrm{mL}$, which is likely a result of sublimation. Therefore, false-negative results are unlikely, but at concentrations below $2.0 \mathrm{ng}$ of $\mathrm{PAG} / \mathrm{mL}$ this effect could potentially result in false-positive diagnoses after application of the correction factor. Therefore, the same procedures, including repeat testing and (or) frost-protected shipping, as suggested for blood, apply to serum samples to ensure correct diagnoses.

The present work showed that freezing of bovine blood and serum samples before analysis considerably affects PAG levels. These findings are of importance to practice, as samples for pregnancy detection might accidentally freeze during shipping in the wintertime. Furthermore, in some situations, it might be desirable to determine the PAG content in samples that have been cryopreserved. Correction factors, as proposed in the present study, therefore have their merit, provided that certainty exists that samples have been subjected to freezing. For this reason, a correction factor was developed to reduce the chances of false-positive diagnoses. However, due to concentration-dependent effects of freezing on PAG levels, different correction factors are suggested for different levels of PAG. For levels less than $2.7 \mathrm{ng}$ of $\mathrm{PAG} / \mathrm{mL}$ of blood, no reliable diagnosis

Table 1. Mean differences (diff.) $\pm \mathrm{SD}$ (ng of PAG/mL) between frozen and fresh samples and lower (Lbound) and upper bound (Ubound) of the $95 \%$ confidence intervals for groups based on different PAG levels in frozen blood/serum

\begin{tabular}{|c|c|c|c|c|}
\hline $\begin{array}{l}\text { Group } \\
\text { (ng/mL) }\end{array}$ & Mean diff. & SD & Ubound & Lbound \\
\hline \multicolumn{5}{|l|}{ Blood } \\
\hline $0.4-1.9$ & -0.64 & 0.49 & 0.33 & -1.61 \\
\hline $2.0-3.9$ & -1.28 & 0.99 & 0.67 & -3.23 \\
\hline $4.0-7.9$ & -2.78 & 1.55 & 0.25 & -5.80 \\
\hline $8.0-15.9$ & -6.52 & 5.19 & 3.65 & -16.69 \\
\hline $16.0-31.9$ & -7.73 & 6.05 & 4.12 & -19.58 \\
\hline $32.0-63.9$ & -14.18 & 7.30 & 0.13 & -28.47 \\
\hline $64.0-127.9$ & -21.02 & 10.47 & -0.50 & -41.54 \\
\hline \multicolumn{5}{|l|}{ Serum } \\
\hline $0.4-1.9$ & 0.33 & 0.33 & 0.98 & -0.32 \\
\hline $2.0-3.9$ & 0.89 & 0.54 & 1.94 & -0.17 \\
\hline $4.0-7.9$ & 0.25 & 2.76 & 5.66 & -5.16 \\
\hline $8.0-15.9$ & -0.56 & 5.03 & 9.30 & -10.41 \\
\hline $16.0-31.9$ & -2.32 & 5.65 & 8.76 & -13.40 \\
\hline $32.0-63.9$ & -1.51 & 9.35 & 16.82 & -19.84 \\
\hline $64.0-127.9$ & -7.86 & 14.06 & 19.70 & -35.42 \\
\hline
\end{tabular}


can be given if the sample was potentially exposed to freezing. For economic as well as animal welfare reasons, in these cases, a second sample, which was not subjected to temperatures below freezing, should be drawn in the case of doubt, and insulating packaging material used to ensure that samples are not exposed to temperatures below zero. It might well be that the correction factors generated in the present study are applicable only under conditions prevailing in our laboratory rather than being universally applicable. If this turns out to be the case, each laboratory would be well advised to calculate their own set of correction factors to be able to deal with samples that have been exposed to freezing temperatures.

\section{REFERENCES}

Bland, J. M., and D. G. Altman. 1986. Statistical methods for assessing agreement between two methods of clinical measurement. Lancet i:307-310.

Friedrich, M., and W. Holtz. 2004. Establishment of an ELISA to assess PAG-concentrations in blood and milk of dairy cows. Reprod. Abstr. Ser. 31:21.

Friedrich, M., and W. Holtz. 2010. Establishment of an ELISA for measuring bovine pregnancy-associated glycoprotein in serum or milk and its application for early pregnancy detection. Reprod. Domest. Anim. 45:142-146.

Green, J. A., T. E. Parks, M. P. Avalle, B. P. Telugu, A. L. McLain, A. J. Perterson, W. McMillan, N. Mathialagan, R. R. Hook, S. Xie, and R. M. Roberts. 2005. The establishment of an ELISA for the detection of pregnancy-associated glycoproteins (PAGs) in the serum of pregnant cows and heifers. Theriogenology 63:1481-1503.
Grouven, U., R. Bender, A. Ziegler, and S. Lange. 2007. Vergleich von Messmethoden. Dtsch. Med. Wochenschr. 132:e69-e73.

Hoedemaker, M., R. Mansfeld, and A. de Kruif. 2007: Kennzahlen zur Beurteilung der Fruchtbarkeit. Pages 31-32 in Tierärztliche Bestandsbetreuung beim Milchrind. 2nd ed. A. de Kruif, R. Mansfeld, and M. Hoedemaker, ed. Enke Verlag, Stuttgart, Germany.

Hughes, A. L., J. A. Green, J. M. Garbayo, and R. M. Roberts. 2000. Adaptive diversification within a large family of recently duplicated, placentally expressed genes. Proc. Natl. Acad. Sci. USA 49:3319-3323

Kraft, W. 2006. Fehlermöglichkeiten. Pages 33-34 in Klinische Labordiagnostik in der Tiermedizin. 6th ed. W. Kraft and U. M. Dürr, ed. Schattauer GmbH, Stuttgart, Germany.

Kroll, M. H., and R. J. Elin. 1994. Interference with clinical laboratory analyses. Clin. Chem. 40:1996-2005.

Lippi, G., G. C. Guidi, C. Mattiuzzi, and M. Plebani. 2006. Preanalytical variability: The dark side of the moon in laboratory testing. Clin. Chem. Lab. Med. 44:358-365.

Lührmann, B. 2011. Fruchtbarkeit-Rechnet sich das? In 29th Scientific Symposium, Güstrow, Germany. Landeskontrollverband für Leistungs- und Qualitätsprüfung, Mecklenburg-Vorpommern e.V., Güstrow, Germany.

Sasser, R. G., C. A. Ruder, K. A. Ivani, J. E. Butler, and W. C. Hamilton. 1986. Detection of pregnancy by radioimmunoassay of a novel pregnancy-specific protein in serum of cows and a profile of serum concentrations during gestation. Biol. Reprod. 35:936-942.

Stahmann, F., Gauly, M., Holtz, W. 2012. Potentielle präanalytische Fehlerquellen beim PAG- Trächtigkeitstest. Page D22 in Scientific Symposium of the German Society for Animal Breeding (DGfZ) 2012. University of Halle-Wittenberg, Halle, Germany.

Zoli, A. P., J.-F. Beckers, P. Wouters-Ballman, J. Closset, P. Falmagne, and F. Ectors. 1991. Purification and characterization of bovine pregnancy-associated glycoprotein. Biol. Reprod. 45:1-10.

Zoli, A. P., L. A. Guilbault, P. Delahaut, W. Benitez Ortiz, and J.-F. Beckers. 1992. Radioimmunoassay of a bovine pregnancy-associated glycoprotein in serum: Its application for pregnancy diagnosis. Biol. Reprod. 46:83-92. 